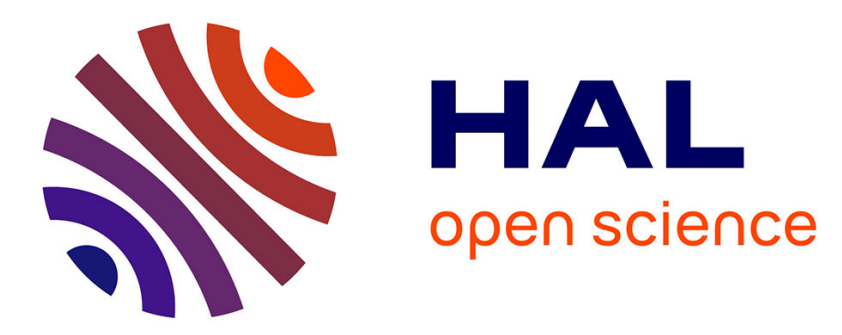

\title{
Reverse transcriptase and substrate dependence of the RNA hypermutagenesis reaction
}

\author{
Miguel Angel Martinez, Monica Sala, Jean Pierre Vartanian, S Wain-Hobson,
} Simon Wain-Hoboson

\section{- To cite this version:}

Miguel Angel Martinez, Monica Sala, Jean Pierre Vartanian, S Wain-Hobson, Simon Wain-Hoboson. Reverse transcriptase and substrate dependence of the RNA hypermutagenesis reaction. Nucleic Acids Research, 1995, 23 (14), pp.2573-2578. 10.1093/nar/23.14.2573 . pasteur-03520153

\section{HAL Id: pasteur-03520153}

\section{https://hal-pasteur.archives-ouvertes.fr/pasteur-03520153}

Submitted on 10 Jan 2022

HAL is a multi-disciplinary open access archive for the deposit and dissemination of scientific research documents, whether they are published or not. The documents may come from teaching and research institutions in France or abroad, or from public or private research centers.
L'archive ouverte pluridisciplinaire HAL, est destinée au dépôt et à la diffusion de documents scientifiques de niveau recherche, publiés ou non, émanant des établissements d'enseignement et de recherche français ou étrangers, des laboratoires publics ou privés.

\section{(c)(1)}

Distributed under a Creative Commons Attribution| 4.0 International License 


\title{
Reverse transcriptase and substrate dependence of the RNA hypermutagenesis reaction
}

\author{
Miguel Angel Martínez,, Monica Sala, Jean-Pierre Vartanian and Simon Wain-Hobson*
}

\author{
Unité de Rétrovirologie Moléculaire, Institut Pasteur, 28 rue du Dr. Roux, 75724 Paris Cedex 15, France
}

Recelved May 17, 1995; Revised and Accepted June 14, 1995

\begin{abstract}
$G \rightarrow A$ hypermutation is a remarkable phenomenon resulting from retroviral reverse transcription in the presence of highly biased dNTP concentrations. Of the three reverse transcriptases (RTases) available, those of human immunodeficlency virus type 1 (HIV-1), avian myeloblastosis virus (AMV) and Moloney murine leukemia virus (MoMLV), the HIV-1 enzyme showed the greatest sensitivity to blased [dCTP]/dTTP] ratios. The HIV-1 RTase was able to discriminate between dUTP, dITP and the four DNA precursors and was insensitive to $\mathrm{pH}$. There was little preference for nucleotide contexts. A fow exceptlonally modified sequences were found presumably resulting from $G \rightarrow A$ hypermutation and multiple strand transfer. This particular predilection of the HIV-1 and, by extrapolation, the lentiviral RTases towards $\mathbf{G} \rightarrow \mathbf{A}$ hypermutation suggests that the phenomenon may have contributed to the remarkably elevated $A$ content of these retroviral genomes.
\end{abstract}

\section{INTRODUCTION}

Most organisms have evolved to ensure fidelity in DNA replication. RNA viruses and retroviruses live at the edge in that their replication fidelity borders on the poorest compatible with survival. Typically error rates are in the range of 0.03-2 substitutions per genome per replicative cycle (1). These values are in sharp contrast to those for DNA based microbes $(0.0015$ substitutions per genome per cycle; 2 ). However, there is nothing to prohibit lower fidelity rates per se apart from viability. Indeed, among RNA viruses three forms of hypermutation, $A \rightarrow I, G \rightarrow A$ and insertional hypermutation have been described. The former arises from post-transcriptional modification of RNA by double stranded RNA adenosine deaminase $(3,4)$. The latter, in which four single bases were inserted at different sites, was found in a retrovirus during a single cycle of replication and remains a unique observation (5).

$\mathrm{G} \rightarrow \mathrm{A}$ hypermutation occurs during retroviral DNA synthesis in which $\mathrm{G}$ residues are found monotonously substituted by $A$ $(6-8)$. For some stretches $\leq 60 \%$ of all $G$ are replaced by $A(9,10)$. It is particularly striking for the lentivirus subfamily of retroviruses such as the human and simian immunodeficiency viruses
(HIV-1, HIV-2 and SIV), equine infectious anaemia virus (EIAV) and caprine arthritis encephalitis virus (CAEV) $(9,11-13)$. The penchant for extensive $\mathrm{G} \rightarrow \mathrm{A}$ hypermutation among the lentiviruses might be a particular trait of the lentiviral RTase, although there is currently insufficient data for other retroviruses to draw this conclusion (6). The phenomenon was hypothesized to result from reverse transcription in the presence of a highly biased intracellular [dCTP]/[dTTP] pools, and therefore be coincident with DNA polymerization. Recently this has been confirmed in an in vitro reaction involving RNA, the HIV-1 RTase and biased dNTPs (14). An inverse relationship was noted between fidelity and the magnitude of the [dCTP]/[dTTP] bias.

$\mathrm{G} \rightarrow \mathrm{A}$ hypermutation results from polymerization involving multiple rG:dT mismatches (14). The stability of this most stable of base mismatches (15) suggested that reverse transcription with biased deoxypurine triphosphate pools would generate $U \rightarrow C$ hypermutants resulting from polymerization involving multiple $\mathrm{rU}: \mathrm{dG}$ mismatches. This turned out to be the case although the degree of hypermutation was somewhat less (14). A consequence of G:T mispairing is a slight displacement of both bases and greater exposure of the 5-methyl group of $\mathrm{T}$ and the 2-amino groups of $\mathrm{G}$ into the major/minor grooves (15). Accordingly it might be expected that the use of dUTP or deoxyinosine triphosphate (dITP), devoid of the offending methyl group and amino groups, might give rise to a more stable base pair and more extensive hypermutagenesis if substituted for dTTP and dGTP, respectively. Furthermore, as dITP is capable of hydrogen bonding to $\mathrm{rC}$ and $\mathrm{rU}$ it is possible that its use in the hypermutagenesis reaction might broaden the spectrum of substitutions which are currently confined to the monotonous types i.e. $\mathrm{G} \rightarrow \mathrm{A}, \mathrm{U} \rightarrow \mathrm{C}, \mathrm{A} \rightarrow \mathrm{G}, \mathrm{C} \rightarrow \mathrm{U}$ and the $\mathrm{G} \rightarrow \mathrm{A}+\mathrm{U} \rightarrow \mathrm{C}$ and $A \rightarrow G+C \rightarrow U$ mixtures (14). Here it is shown how different retroviral RTases, $\mathrm{pH}$, the use of dUTP and dITP, and other dNTP pool biases impinge upon the hypermutagenesis reaction.

\section{MATERIALS AND METHODS}

A M13mp18 clone containing the env V1-V2 regions of HIV-1 B40 (7) was PCR-amplified with oligonucleotide 1 (5'-GCGAAGCTTCAAAGCCTAAAGCCATGTGTA) and oligonucleotide 2 (5'-GCGGAATTCTAATGTATGGGAATTGGCTCAA). The 317 bp DNA fragment, with unique HindIII and EcoRI restriction sites (bold face), was digested and ligated into a pBluescript $\mathrm{SK}^{+}$vector. The resulting plasmid $(1 \mu \mathrm{g})$ was

\footnotetext{
* To whom comespondence should be addressed
} 
digested with EcoRI, and used as a substrate for in vitm transcription using T7 RNA polymerase as described (14). RNA was phenol extracted and ethanol precipitated. The reverse transcription reaction buffer was $50 \mathrm{mM}$ HEPES ( $\mathrm{pH} 7$ ), $15 \mathrm{mM}$ MgAspartate, $10 \mathrm{mM}$ DTT, $130 \mathrm{mM} \mathrm{KAcetate,} 15 \mathrm{mM} \mathrm{NaCl}$, and varying dNTP concentrations (Table 1). Oligonucleotide 3 (5'-GCGTCTAGAAGTATCATTATCTATTGGTA; 2 pmol), complementary to positions $199-228$ of the 317 bp plus strand DNA fragment, was annealed to $0.5 \mathrm{pmol}$ of the template RNA in $50 \mu \mathrm{l}$ of the reaction by first heating to $65^{\circ} \mathrm{C}$ for $1 \mathrm{~min}$ followed by incubation at $37^{\circ} \mathrm{C}$ for $1 \mathrm{~min}$, after which $15 \mathrm{pmol}(6.25 \mathrm{U})$ of either the HIV-1 RTase (Boehringer), AMV RTase (Promega) or MoMLV RTase (Gibco) and RNase inhibitor $(0.3 \mathrm{U} / \mu \mathrm{l}$ final concentration, Pharmacia) were added. The reaction was incubated at $37^{\circ} \mathrm{C}$ for $3 \mathrm{~h}$. Deoxynucleotide triphosphates were purchased from Pharmacia while dUTP, dITP and ITP were from Boehringer.

In order to recover sufficient material for subsequent cloning, cDNA was amplified by 12 cycles of PCR with oligonucleotide 3 and oligonucleotide 4 (5'-GCGGTCGACCAAAGCCTAAAGCCA) producing a 231 bp DNA fragment with restriction sites at its ends, $X b a I$ and $S a l l$ respectively (bold face; 14 ). The specific $231 \mathrm{bp}$ PCR fragments were purified from a $2 \%$ low melting point agarose gel, digested with $\mathrm{XbaI}$ and Sall, ligated into M $13 \mathrm{mp} 18$ RF DNA and transformed into E.coli XL-1 blue. Clones were sequenced by the standard dideoxy method using M13 universal primer.

\section{RESULTS}

\section{HIV-1 RTase undertakes hypermutagenesis more efficiently}

The frequency distribution of $G \rightarrow A$ transitions per clone generated by reverse transcription by either of the three RTases is given in Figure 1. The enzymes differed considerably in their ability to accomplish $\mathrm{G} \rightarrow \mathrm{A}$ hypermutation, the HIV-1 enzyme proved to be the most sensitive to reduced dCTP concentrations, the MoMLV RTase the least. For HIV-1, AMV and MoMLV RTases the maximum number of substitutions per clone was, respectively, 8, 6 and 2 at $30 \mathrm{nM}$ dCTP and 12,7 and 3 at $10 \mathrm{nM}$ $\mathrm{dCTP}$, respectively. The mean number of transitions per clone was $2.5,1.5$ and 0.3 for the $30 \mathrm{nM}$ dCTP HIV-1, AMV and MoMLV RTase reactions and 4.3, 2.8 and 0.7 for the $10 \mathrm{nM}$ dCTP reaction.

The mean frequency of $G \rightarrow A$ transitions $\left(\bar{f}_{G} \rightarrow A\right)$ per data set may be calculated as the number of transitions/(number of clones sequenced $\times$ number of $G$ residues in sequence, i.e. 32 ) and are given in Table 1 . The frequency of $G \rightarrow A$ transitions $\left(\vec{f}_{G} \rightarrow A\right.$ or simply f) clearly varies as a function of [dCTP] the relationship being, for small values of $\overline{\mathrm{f}}, \overline{\mathrm{f}} /(1-\overline{\mathrm{f}})=[\mathrm{dTTP}] / \mathrm{dCTP}] \Sigma \alpha_{i} / 32$, where $\alpha_{i}=\left[\left(V_{\max } / K_{\mathrm{m}}\right)_{\mathrm{dTTP}}\right]_{\mathrm{i}} /\left[\left(V_{\max } / K_{\mathrm{m}}\right)_{\mathrm{dCTP}}\right]_{\mathrm{i}}$ and $\mathrm{i}=1-32(16)$. In the absence of individual values of $\alpha_{j}$ for each site they were taken to be equal and constant for each of the $32 \mathrm{G}$ residues, effectively assuming no effect of sequence context (vide infra). In the present conditions where [dCTP] [RNA], [dCTP] is exhausted as polymerization proceeds, and consequently the length of the sequence being explored is decreasing. From this it results that the plot of $\overline{\mathrm{f}} /(1-\overline{\mathrm{f}})$ versus $1 /[\mathrm{dCTP}]$ is curved downwards with decreasing [dCTP], $\overline{\mathrm{f}}$ being only correctly estimated from the initial slope of the plot (Fig. 1 inserts). A plot
Table 1. Base substitution frequencies accompanying reverse transcoption in the presence of biased dNTP pools as a function of RTase, substrate, template composition and $\mathrm{pH}$

\begin{tabular}{|c|c|c|c|c|c|c|c|}
\hline \multirow{2}{*}{$\begin{array}{l}\text { dNTP } \\
\text { Bias }\end{array}$} & \multirow{2}{*}{$\begin{array}{c}\text { Reverse } \\
\text { Transcriptase }\end{array}$} & \multicolumn{4}{|c|}{$\mathrm{dNTPs} / \mu \mathrm{M}$} & \multicolumn{2}{|c|}{ Substitutions } \\
\hline & & $\mathrm{T}$ & c & G & A & $G \rightarrow A$ & $\overline{\mathfrak{f}}_{\mathrm{G} \rightarrow \mathrm{A}}$ \\
\hline$T>>C$ & HIV-1 & $\begin{array}{l}440 \\
440 \\
440 \\
440\end{array}$ & $\begin{array}{c}0.1 \\
0.03 \\
0.01 \\
0.003\end{array}$ & $\begin{array}{l}20 \\
20 \\
20 \\
20\end{array}$ & $\begin{array}{l}40 \\
40 \\
40 \\
40\end{array}$ & $\begin{array}{c}47 \\
483 \\
866 \\
63\end{array}$ & $\begin{array}{l}3.8 \times 10^{-2} \\
7.9 \times 10^{-2} \\
1.3 \times 10^{-1} \\
1.7 \times 10^{-1}\end{array}$ \\
\hline$T>>C$ & AMV & $\begin{array}{l}440 \\
440 \\
440\end{array}$ & $\begin{array}{l}0.1 \\
0.03 \\
0.01\end{array}$ & $\begin{array}{l}20 \\
20 \\
20\end{array}$ & $\begin{array}{l}40 \\
40 \\
40\end{array}$ & $\begin{array}{l}8 \\
60 \\
79\end{array}$ & $\begin{array}{l}1.2 \times 10^{-2} \\
4.6 \times 10^{-2} \\
9.4 \times 10^{-2}\end{array}$ \\
\hline \multirow[t]{2}{*}{$T \gg>C$} & MoMLV & $\begin{array}{l}440 \\
440 \\
440\end{array}$ & $\begin{array}{l}0.1 \\
0.03 \\
0.01\end{array}$ & $\begin{array}{l}20 \\
20 \\
20\end{array}$ & $\begin{array}{l}40 \\
40 \\
40\end{array}$ & $\begin{array}{c}5 \\
12 \\
17\end{array}$ & $\begin{array}{l}8.2 \times 10^{-3} \\
9.8 \times 10^{-3} \\
2.1 \times 10^{-2}\end{array}$ \\
\hline & & U & c & G & A & $G \rightarrow A$ & $\bar{I}_{G \rightarrow A}$ \\
\hline \multirow[t]{2}{*}{$U \gg>C$} & HIV-1 & $\begin{array}{l}440 \\
440 \\
440 \\
440\end{array}$ & $\begin{array}{c}0.1 \\
0.03 \\
0.01 \\
0.003\end{array}$ & $\begin{array}{l}20 \\
20 \\
20 \\
20\end{array}$ & $\begin{array}{l}40 \\
40 \\
40 \\
40\end{array}$ & $\begin{array}{c}4 \\
10 \\
12 \\
6\end{array}$ & $\begin{array}{l}1.1 \times 10^{-2} \\
1.6 \times 10^{-2} \\
3.1 \times 10^{-2} \\
3.9 \times 10^{-2}\end{array}$ \\
\hline & & $\mathbf{T}$ & c & G & A & $C \rightarrow A$ & $\bar{f}_{C \rightarrow A}$ \\
\hline \multirow[t]{2}{*}{$T \gg>G$} & HIV-1 & $\begin{array}{l}440 \\
440\end{array}$ & $\begin{array}{l}10 \\
10\end{array}$ & $\begin{array}{c}0.01 \\
0.003\end{array}$ & $\begin{array}{l}40 \\
40\end{array}$ & $\begin{array}{l}5 \\
2\end{array}$ & $\begin{array}{l}9 \times 10^{-3} \\
8 \times 10^{-3}\end{array}$ \\
\hline & & $\mathrm{T}$ & C & G & A & $C \rightarrow T$ & $\overline{\mathrm{I}}_{\mathrm{C} \rightarrow \mathrm{T}}$ \\
\hline \multirow[t]{2}{*}{$A>>G$} & HIV-1 & 44 & 100 & 0.03 & 400 & 1 & $1.5 \times 10^{-3}$ \\
\hline & & $\mathrm{T}$ & C & $G$ & A & $A \rightarrow G$ & $\bar{f}_{A \rightarrow G}$ \\
\hline \multirow[t]{2}{*}{$\mathrm{C} \gg \mathrm{T}$} & HIV-1 & 0.01 & 100 & 20 & 40 & 4 & $5.2 \times 10^{-3}$ \\
\hline & HIV-1 & $\begin{array}{c}T \\
44\end{array}$ & $\begin{array}{l}C \\
10\end{array}$ & $\begin{array}{c}\text { I } \\
200\end{array}$ & $\begin{array}{c}\mathrm{A} \\
0.03\end{array}$ & $\begin{array}{c}\mathrm{U} \rightarrow \mathrm{C} \\
0\end{array}$ & $\begin{array}{l}\bar{f}_{U \rightarrow C} \\
<2 \times 10^{-3}\end{array}$ \\
\hline \multicolumn{2}{|c|}{ Inosine in RNA } & $T$ & C & G & A & $G \rightarrow A$ & $\overline{\mathfrak{f}}_{\mathrm{G} \rightarrow \mathrm{A}}$ \\
\hline $\mathrm{T} \gg>\mathrm{C}$ & HIV-1 & 440 & 0.1 & 20 & 40 & 36 & $5.2 \times 10^{-2}$ \\
\hline$T>>C$ & $\begin{array}{l}\mathrm{HIV}-1 \\
\mathrm{pH} 8\end{array}$ & $\begin{array}{c}T \\
440 \\
440 \\
440\end{array}$ & $\begin{array}{c}C \\
0.1 \\
0.03 \\
0.01\end{array}$ & $\begin{array}{l}G \\
20 \\
20 \\
20\end{array}$ & $\begin{array}{l}A \\
40 \\
40 \\
40\end{array}$ & $\begin{array}{c}G \rightarrow A \\
6 \\
30 \\
78\end{array}$ & $\begin{array}{l}\overline{\mathrm{f}}_{\mathrm{G} \rightarrow \mathrm{A}} \\
9 \times 10^{-3} \\
5.5 \times 10^{-2} \\
1.2 \times 10^{-1}\end{array}$ \\
\hline
\end{tabular}

$\bar{f}_{G} \rightarrow A$ was calculated as number of $G \rightarrow A$ substitutions/(32 Gs in target sequence $\times$ no. clones analysed). The substitution frequencies for other reactions were calculated in an analogous manner.

of $\bar{f} /(1-\bar{f})$ versus $\log [\mathrm{dCTP}]$ empirically takes into account a correction for the exhaustion of [dCTP] (Fig. 1).

A comparison of $\overline{\mathrm{f}} /(1-\overline{\mathrm{f}})$ versus $\log [\mathrm{dCTP}]$ for the three $\mathrm{RTases}$ (Fig. 2A) confirms that $\mathrm{G} \rightarrow$ A hypermutation most readily occurs during cDNA synthesis using the HIV-1 RTase. The AMV enzyme was perfectly capable of producing hypermutants although they were detected under slightly more biased pool concentrations, as evidenced by the displacement of the gradient to lower [dCTP] values. Despite this it showed a comparable concentration dependence, i.e. $d \bar{f} /(1-\bar{f}) / d[d C T P]$, to the HIV-1 RTase. By contrast the MoMLV RTase showed a much reduced concentration dependence. Because of these findings the HTV-I RTase was used in all subsequent experiments.

\section{pH and substrate analogues}

A correlation between increased $\mathrm{pH}$ and decreased fidelity of the HIV-1 RTase has been noted for DNA-dependent DNA syntheses 

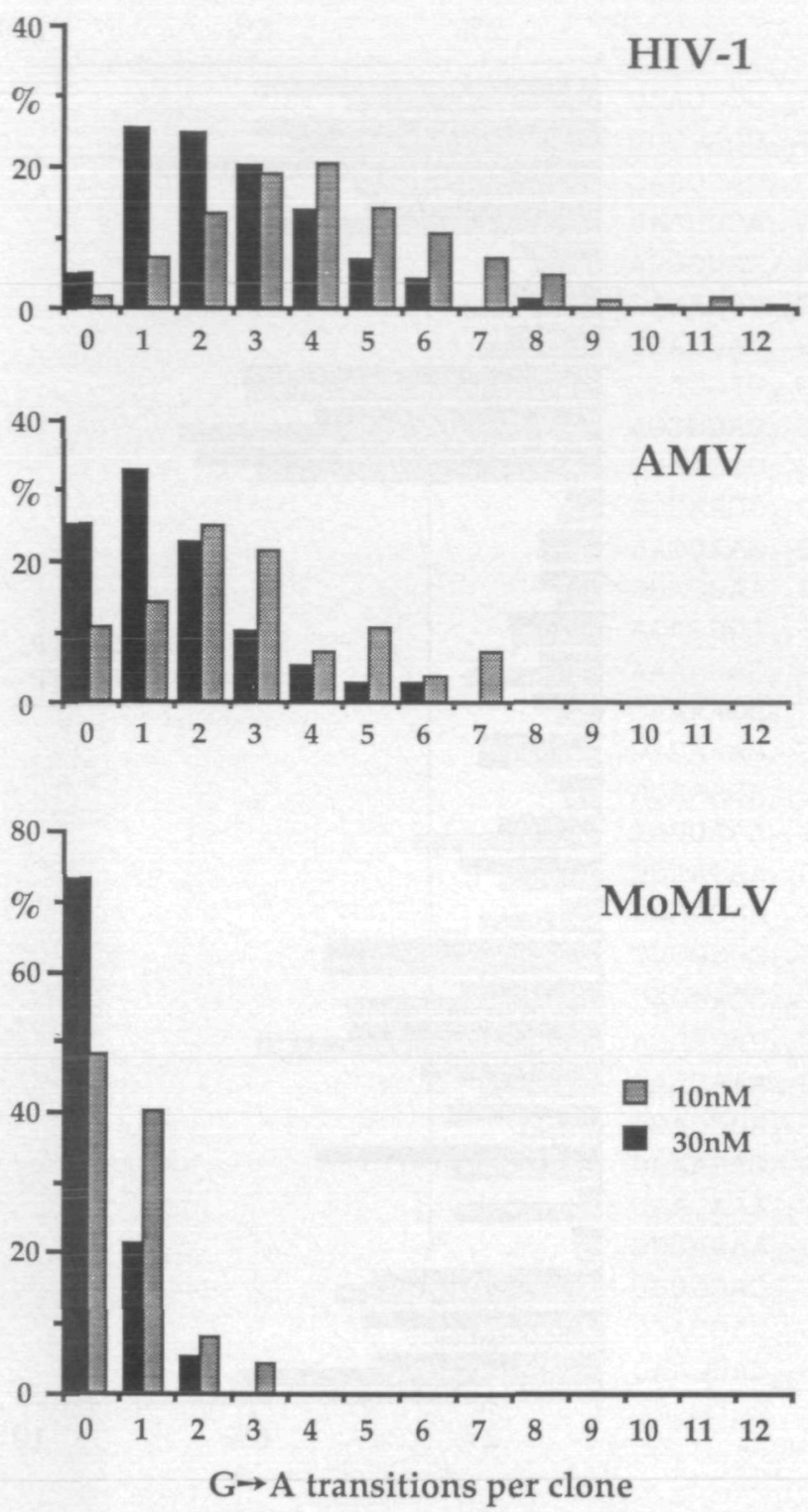

Figure 1. Frequency distribution of $\mathrm{G} \rightarrow \mathrm{A}$ transitons in hypermutated sequences for three RTases. Data is given for two hypermutagenesis reactions employing different dCTP concentratuons, notably 10 and $30 \mathrm{nM}$ while the [dTTP] was $440 \mu \mathrm{M}$. With decreasing [dCTP] the number of hypermutated clones increased ( 0 substitutions $=$ wild type) as did the average number of transituons per clone.

and most notably for G:T mismatches (17). Furthermore, rG:dT misincorporation on a RNA template in a steady state primer elongation assay was slower at $\mathrm{pH} 7$ than $\mathrm{pH} 8$ again suggesting a possible influence of $\mathrm{pH}$ upon fidelity (18). Despite these observations the relationship of $\mathrm{pH}$ on the frequency of $\mathrm{G} \rightarrow \mathrm{A}$ hypermutation in fact showed only a very slight difference, statistically insignificant, between fidelity at $\mathrm{pH} 7$ and $\mathrm{pH} 8$ as a function of dCTP concentration (Table 1; Fig. 2B).

The substitution of dUTP in lieu of dTTP greatly reduced the concentration dependence of $\mathrm{G} \rightarrow \mathrm{A}$ hypermutation by the HIV-1 RTase (Table 1; Fig. 2C). The use of dITP in place of dGTP did not significantly change the mean substitution frequency of the HIV-1 enzyme in the context of $U \rightarrow C$ hypermutation (Table 1 ).
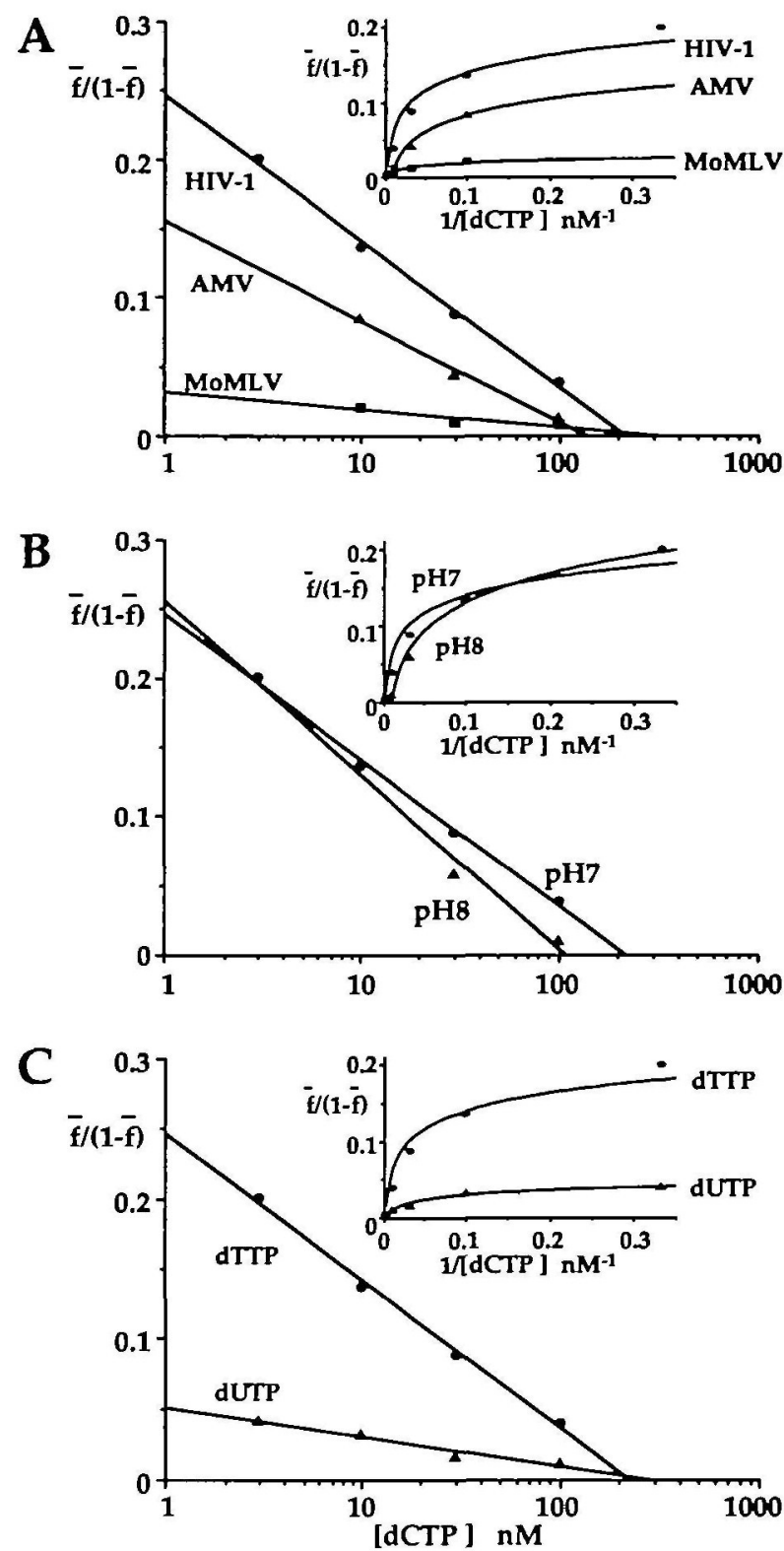

Figure 2. Mean base substitution frequencies, 7 , accompanying retroviral synthesis in the presence of highly biased [dCTP]/dTTP] ratios. The [dTTP] concentration was $440 \mu \mathrm{M}$. (A) Comparison of three RTases from HIV-1, avian myeloblastosis virus (AMV) and Moloney murine leukemia virus (MoMLV). (B) $\mathrm{pH}$ dependence of the base substitution frequency. (C) Substitution of dUTP in lieu of dTTP in the hypenmutagenesis reaction. The inserts show the relation between $f /(1-\widehat{f})$ and $[\mathrm{dCTP}]^{-1}$.

However, the efficiency of cDNA synthesis, already rather poor due the highly biased [dATP]/[dGTP] ratio, was even further reduced when dGTP was substituted for dITP (data not shown). In an attempt to overcome this handicap RNA was synthesized in which the GTP substrate was replaced by ITP. Reverse transcription with a highly biased [dCTP]/[dTTP] ratio resulted in only slightly more efficient $G \rightarrow A$ hypermutation (Table 1). No other mutations were noted. However, even less product was recovered after PCR than usual indicating that the RTase had difficulties in elongating beyond rl:dT mismatches. 


\section{Other forms of hypermutation?}

$\mathrm{G} \rightarrow \mathrm{A}$ and $\mathrm{U} \rightarrow \mathrm{C}$ hypermutation result from elongation beyond $\mathrm{rG}: \mathrm{dT}$ and $\mathrm{rU}: \mathrm{dG}$ mismatches, probably because of all the 12 possible mismatches, the G:T mismatch is the most stable (15). Nonetheless, other dNTP pool biases, notably low [dGTP]/high [dATP] and low [dTTP]/high [dCTP] were investigated which could lead to rC:dA and rA:dC mismatches. However, despite dNTP biases of $\sim 10^{-4}$, the frequency of $\mathrm{C} \rightarrow \mathrm{T}$ and $\mathrm{A} \rightarrow \mathrm{G}$ transitions remained very low (Table 1). Furthermore, a [dGTP]/[dTTP] bias of $\sim 10^{-4}$ failed also to produce a high frequency of $\mathrm{C} \rightarrow \mathrm{A}$ substitutions indicating that elongation beyond the rC:dT mismatch posed problems for the HIV-1 RTase (Table 1). In all three cases the recovery of full length product was less efficient than for hypermutagenesis involving deoxypyrimidine or deoxypurine nucleotide biases.

\section{Oligopurine 'cool' spots}

The widespread use of hypermutagenesis as a means to alter nucleic acid sequences requires that there be few hot and cold spots. In the initial study few were noted although the mean number of $G \rightarrow A$ transitions per site, -4.5 , was rather low such that the identification of such sites was not possible with precision (14). In order to generate a large data base $-200 \mathrm{G} \rightarrow \mathrm{A}$ hypermutated clones from each of the $10 \mathrm{nM}$ and $30 \mathrm{nM} \mathrm{dCTP}$ reactions were sequenced and the context surrounding $G \rightarrow A$ substitutions scored (Fig. 3). For the $10 \mathrm{nM}$ and $30 \mathrm{nM}$ dCTP reactions 866 and 483 transitions were scored yielding mean substitution frequencies per site of 27 and 15 , respectively. There were no hot or cold spots and few major differences between the two data sets. However, hypermutation was slightly less frequent in the oligopurine rich regions, particularly between $\mathrm{G}_{11-19}$. An analysis of the context surrounding sites of more- and less-thanaverage substitution revealed that an elevated purine and low $C$ content (mean composition $\mathrm{U}=1.2, \mathrm{C}=0.5, \mathrm{G}=1.7$ and $\mathrm{A}=3.7$ ) within the seven bases $3^{\prime}$ to the site of substitution was not too conducive to hypermutation in vitro. By contrast an elevated $\mathrm{C}$ and depressed $A$ content characterized the frequently substituted sites (i.e. $\mathrm{U}=2.1, \mathrm{C}=1.8, \mathrm{G}=1.2$ and $\mathrm{A}=2.0$ ). The average composition of the seven bases $3^{\prime}$ to the $32 \mathrm{G}$ target residues was $(\mathrm{U}=1.8, \mathrm{C}=1.1, \mathrm{G}=1.3, \mathrm{~A}=2.9$ ).

Among this large collection of hypermutated clones two sequences distinguished themselves by the striking presence of long tracts of 24 and $25 \mathrm{~A}$ residues (Fig. 4). Both structures could be explained by repeated hypermutation within an oligopurine tract accompanied by frequent strand displacement, although the precise series of steps can only be conjectured. Template DNA synthesis is mandated given that RTase has no polyA or terminal transferase activity. These clones show once again the remarkable ability of the HIV-1 RTase to undertake efficient strand transfer $(19,20)$.

\section{DISCUSSION}

HIV-1 RTase was clearly capable of performing hypermutagenesis better than the other two enzymes currently available. At -4 fold greater [dCTP]/[dTTP] ratios the AMV RTase was able to generate extensive $G \rightarrow A$ hypermutants. This would suggest that the AMV enzyme has no problems per se with elongation beyond multiple mismatches but discriminated better between correct dCTP and incorrect dTTP incorporation than did the HIV-1

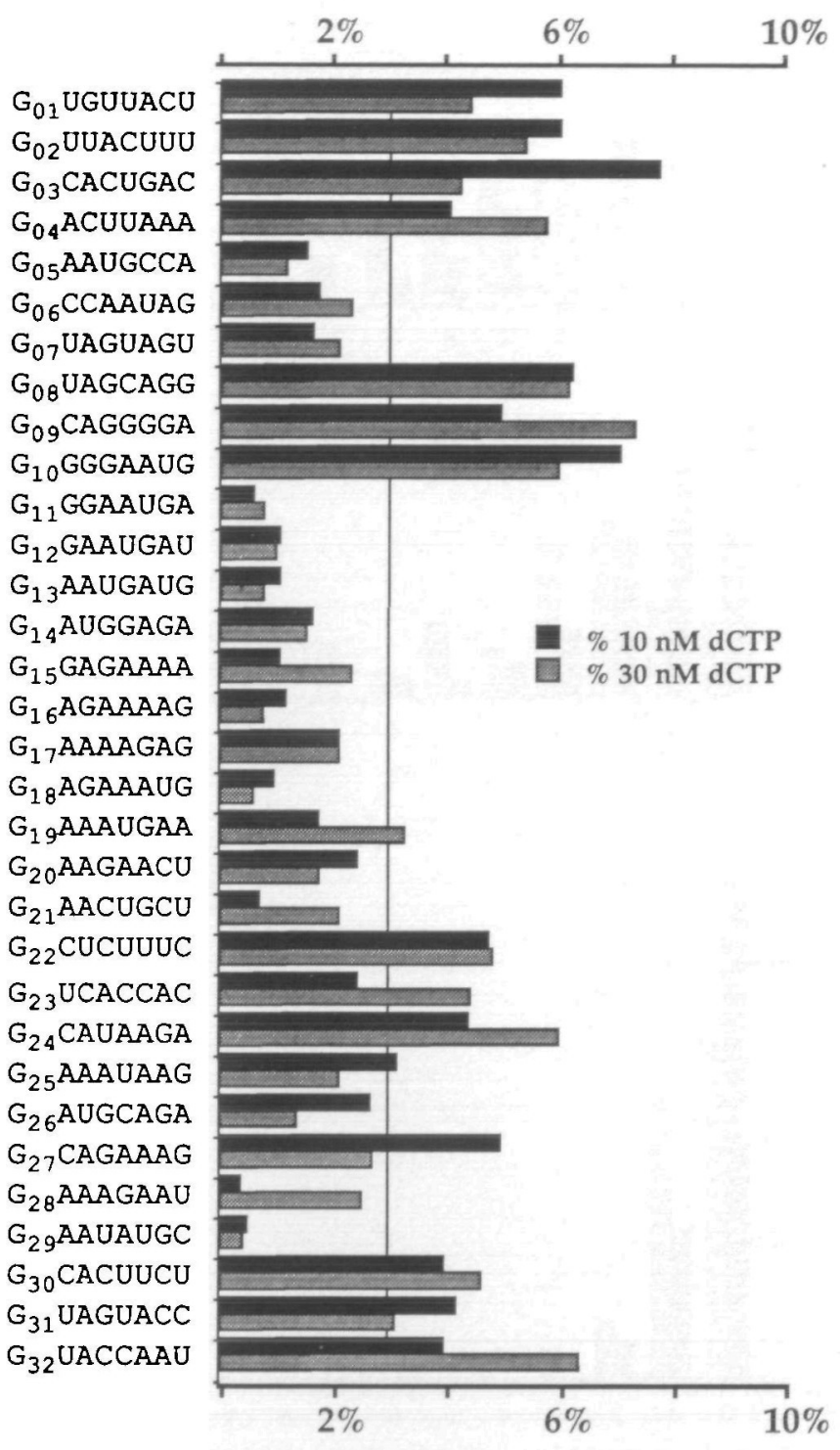

Figure 3. Sequence context influences the distribution of $G \rightarrow A$ transitions in hypermutated sequences. A total of 202 and 190 clones were sequenced from the HIV-1 RTase reactions using $10 \mathrm{nM}$ and $30 \mathrm{nM}$ dCTP (Table 1). The distribution of transitions was normalized to the total number ( 866 and 483 for the 10 and $30 \mathrm{nM} \mathrm{HIV}-1$, respectively). The vertical line gives the average value per site for the combined data sets.

RTase. That $\mathrm{G} \rightarrow \mathrm{A}$ hypermutation has yet to be described for the avian retroviruses could stem from either this decreased sensitivity, the relative dearth of sequence data, or both. From a pragmatic viewpoint the HIV-1 enzyme is to be preferred for in vitro hypermutagenesis. However, there might be situations in the hypermutagenesis of RNA sequences in which only a low density of mutations may be required in which case the AMV RTase would be perfectly appropriate.

Both the HIV-1 and AMV RTases have been shown to elongate efficiently beyond mismatches in vitro, while the MoMLV enzyme is considerably less efficient (21). An interesting parallel is to be found in the structure of the three RTases. Both the HIV and AMV RTases are heterodimers, the HIV-1 heterodimer (p66:p51) resulting from cleavage of the $\mathrm{RNaseH}$ domain in one 


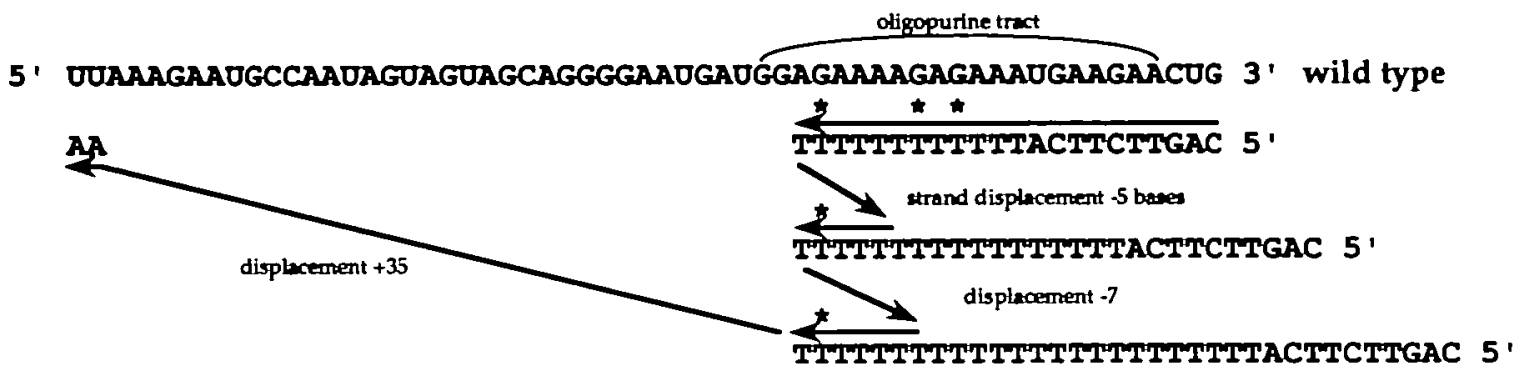

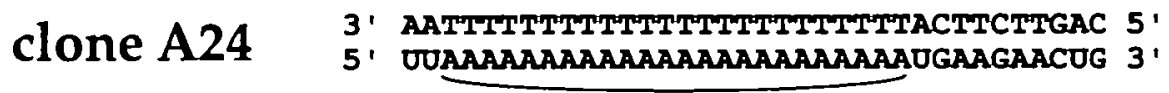

A24

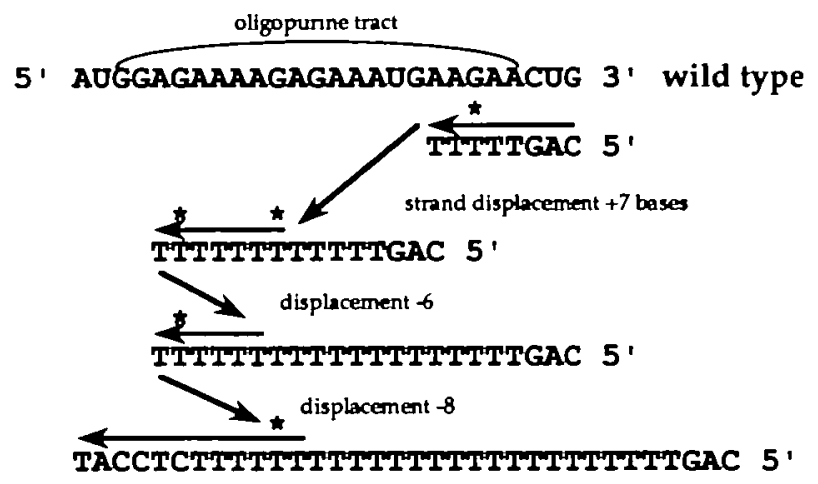

\section{clone A25}

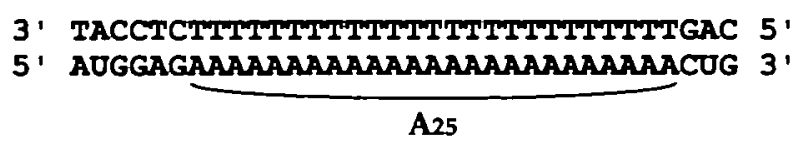

Figure 4. Structure and proposed mechanism for the formation of oligoA bearing clones. Clones A24 and A25 were denved from the HIV-1 RTase reactions using 10 and $30 \mathrm{nM} \mathrm{dCTP}$, respectively. The formation of such sequences must involve RNA templated DNA polymerization as RTase has no polyA or terminal transferase activity. While the proposed steps shown may only be postulated, they represent the most parsimonious solutons.

chain leaving a p51 molecule with a different structure of its four domains $(22,23)$. For the AMV $\alpha \beta$ heterodimer the larger $\beta$ chain encodes the viral integrase due to incomplete protease cleavage at the RTase-IN junction (for review see ref. 24). By contrast the MoMLV enzyme functions as a monomer (24).

The HIV-I enzyme showed exquisite discrimination against dUTP and dITP substrates. Yet when ITP was incorporated into the template elongation was very inefficient although those full length molecules obtained contained slightly more substitutions with respect to the standard reaction. It is as though the enzyme has evolved a simple form of fidelity control allowing discrimination against potential substrates such as dITP and dUTP, found in low concentrations within the cytoplasm. Other dNTP pool imbalances did not yield alternative forms of hypermutation (Table 1), illustrating once again the essential nature of the stable G:T mismatch to the phenomenon of hypermutation.

Variables such as the $\mathrm{pH}$ did not modify the fidelity as might have been anticipated $(17,18)$. This discrepancy might simply be due to methodological differences. These observations pertained kinetic studies in which [template:primer] > [RTase]. However, in the replication complex, as in the hypermutagenesis reaction, there is a 30-50 fold molar excess of RTase. The highly unbalanced [dCTP]/[dTTP] pools conducive to $G \rightarrow A$ hypermutation reduces the velocity of reverse transcription considerably (14). It is probable that such conditions, as well as the molar excess of enzyme, would enable considerable cycling of the RTase and favour misincorporation of dT opposite $\mathrm{rG}$ and subsequent elongation.

A few warm and cool spots were noted. While there were no obvious short range effects ( $\mathrm{Fig}_{1}$. 3) some longer range effects are suspected as the substitution frequencies between sites $\mathrm{G}_{7}$ (G $\left.\mathrm{G}_{7} \mathrm{UAGUAGU}\right), \mathrm{G}_{8} \quad\left(\mathrm{G}_{8} \mathrm{UAGCAGG}\right)$ and $\mathrm{G}_{31} \quad\left(\mathrm{G}_{31} \mathrm{UA}\right.$ GUACC) show. Up to 18 residues of the template-primer complex are in contact with the HIV-1 RTase, in contrast to DNA-dependent DNA polymerases $(22,23,25)$, indicating that the subtleties in the template-primer sequence over this range may impinge upon polymerization fidelity. Two independent observations support this interpretation. Firstly, an in vitro study of the kinetics of $\mathrm{rG}$ :dT mispair formation showed that preformed rG:dT mismatches in the template-primer duplex at positions -6 and/or -9 (with respect to the polymerase active site) resulted in enhanced and reduced discrimination of the $\mathrm{rG}: \mathrm{dC}$ match and rG:dT mismatch, respectively (18). Secondly, discrimination against the polymerization inhibitor ddGTP was enhanced by a 
Glu84Gly mutation in the RTase sequence which contacts the template at position -3 to $-4(26)$. However, despite local differences in frequency of $\mathrm{G} \rightarrow \mathrm{A}$ misincorporation (Fig. 3), from a pragmatic point of view, most targets were accessible to hypermutagenesis.

Data from Figure 3 shows that $G \rightarrow A$ hypermutation is relatively infrequent in oligopurine rich, low $C$ regions, yet the most striking examples found in this study, clones A24 and A25, probably arose via a combination of hypermutation and multiple strand displacements within an oligopurine rich tract. Such events are however rare, representing only $2 / 555 \mathrm{G} \rightarrow \mathrm{A}$ hypermutants analyzed in this study. Perhaps the ongoing formation of an oligoribopurine:oligodeoxyriboT results in curvature of the duplex, known to be associated with certain oligo-dA-oligo-dT duplexes (27), which might favour strand displacement.

$\mathrm{G} \rightarrow \mathrm{A}$ hypermutation, resulting from proviral DNA synthesis in the presence of fluctuating intracellular dNTP pools, is seen to be a particular property of the HIV-1 RTase due to a heightened sensitivity to deoxypyridine triphosphate imbalances. The elevated $\mathrm{A}$ content of all lentivirus genomes with respect to those of all other retroviruses (28), suggests that the evolution of the lentiviral genome has been inexorably influenced by the metabolic states of their host cells.

\section{ACKNOWLEDGEMENTS}

We would like to thank Henri Buc for helpful discussions. This work was supported by grants from the Institut Pasteur and l'Agence Nationale pour la Recherche sur le SIDA (ANRS). M.A.M. was supported by fellowships from the European community and the ANRS. M.S. was supported by fellowships from the Ministero della Sanità (Italy) and the Fondation pour la Recherche Médicale (Sidaction).

\section{REFERENCES}

1 DrakeJ.W. (1993) Proc. Natl. Acad. Sci. USA, 90, 4171-4175.

2 DrakeJ.W. (1991) Proc. Natl. Acad. Sci. USA, 88, 7160-7164.
3 Cattaneo,R. (1994) Curr. Opin. Gen. Dev., 4, 895-900.

4 Polson,A.G. and Bass,B.L. (1994) EMBO J., 13, 5701-5711.

5 Pathak,V.K, and Temin,H.M. (1992) $J$ Virol., 66, 3093-3100

6 Pathak, V.K. and Temin,H.M. (1990) Proc. Natl. Acad. Scı. USA, 87, 6024-6028.

7 Vartanian,J.P., Meyerhans,A., s]s,B. and Wain-Hobson,S. (1991) J. Viml., 65, 1779-1788.

8 Vartanıan,J.P., Meyerhans,A., Sala,M. and Wain-Hobson,S. (1994) Proc. Natl. Acad. Sci. USA, 91, 3092-3096.

9 Wain-Hobson,S., Sonigo,P., Guyader,M., Gazit,A., and Henry,M. (1995) Virology, 209, in press.

10 Borman,A M., Quillent,C., Chameau,P., Kean,C.M. and Clavel,F. (1995) Virology, 208, in press.

11 Gao,F., Yue,F., White,A.T., Pappas,P.G., Barchue,J., Hanson,A.P., Greene,B.M., Sharp,PM., Shaw,G.M. and Hahn,B.H. (1992) Nature, 359, 495-499.

12 Perry,S., Flahenty,T., Kelly,M.T., Clabough,M.J., Tronick,D.L., Coggins, S.R., Whetter,L., Lengel,C.R. and Fuller,F. (1992) J. Virol., 66, 4085-4097.

13 Johnson,P.R., Hamm,T.E., Goldstein,S., Kitov,S., and Hirsch,V.M (1991) Virology, 185, 217-228.

14 Martinez,M.A., VartanianJ.P. and Wan-Hobson,S. (1994) Proc. Natl. Acad. Sci. USA, 91, 11787-11791.

15 Modrich,P. (1987) Annu. Rev. Biochem., 56, 435-466.

16 Fersht,A. (1985) Enzyme structure and mechanism, 2nd. edition, W. H. Freeman and Company, USA, pp 98-120.

17 Eckert,K.A. and Kunkel,T.A. (1993) Nucleic Acids Res., 21, 5212-5220.

18 Sala,M., Wain-Hobson,S. and Schaeffer,F. (1995) EMBO J., in press.

19 Luo,G., and Taylor,J. (1990) J. Virol., 64, 432I-4328.

20 Destefano,J.J., Haber,M., Rodnguez-Rodriguez,L.M., Fay,L. and Barbaro, R.A. (1992) J. Virol., 66, 6370-6378.

21 Rucchetti,M. and Buc,H. (1990) EMBO J., 9, $1583-1593$.

22 Kohlstaedt,L.A., Wand,J., Friedman,J.M., Rice,P.A. and Steitz.T.A. (1992) Science, 256, 1783-1790.

23 Jacobo-Molina,A., Ding,J., Nannı,R.G., Clark,A.D.Jr., Lu,X., Tantillo,C., Williams,R.L., Kamer,G., Ferris,A.L., Clark,P., Hizı,A., Hughes,S.H. and Amold,E. (1993) Proc. Natl. Acad. Sct. USA, 90, 6320-6324.

24 Prasad,V.R. (1993) In Reverse Transcriptase (eds Skalka,A.M. and Goff,S.P.) Cold Spring Harbor Laboratory Press, NY.

25 Pelletier,H., Sawaya,M.R., Kumar,A., Wilson,S.H. and Kraut,J. (1994) Science, 264, 1891-1903.

26 Boyer,P.L.,Tantıllo,C., Jacobo-Molina,A., Nanni,R.G., DingJ , Amюld,E. and Hughes,S.H. (1994) Proc. Natl. Acad. Sci. USA, 91, 4882-4886.

27 Prke,M.A and Tullius, T.D. (1993) Biochemistry, 32, 127-136.

28 Bronson,E.C. and Anderson.J.N. (1994) J. Mol. Evol, 38, 506-532. 